\title{
STRATEGIES OF URBAN REGENERATION IN VULNERABLE AREAS: A CASE STUDY IN CASTELLÓN, SPAIN
}

\author{
MARÍA JOSÉ RUÁ, PATRICIA HUEDO, LORENA CORDANI, MANUEL CABEZA, \\ BEATRIZ SAEZ \& RAQUEL AGOST-FELIP \\ Jaume I University, Spain
}

\begin{abstract}
The 11th Sustainable Development Goal (UNO, 2030) for Sustainable Cities and Communities highlights the role of urbanisation in development and poverty reduction. Accomplishing this goal and promoting the implementation of the New Urban Agenda are crucial for local governments. Within the stated framework, we herein present some strategies of urban regeneration in the area Castalia-La Guinea in Castellón de la Plana (East Spain). The analysed area presents an old urban fabric with high immigration levels and heterogeneous characteristics, and constitutes an urban environment to be regenerated in a broader context. This area was previously defined in one of the complementary studies to develop the new Land-Use Plan in the city. This report defined the areas of rehabilitation, regeneration and urban renewal, which fall in line with Law 5/2014, of 25 July, on Territorial Planning, Urban Planning and Landscape for the Valencian community (Spain). They are considered vulnerable areas that should be prioritised to undertake urban interventions. The approach to revitalise the area was followed by implementing the "Guidelines for the Development of Strategies of Urban Regeneration for Municipalities of the Valencian Community" (Regional Valencian Government, Spain), which permits an in-depth diagnosis and the presentation of some proposals for its regeneration. The aforementioned guidelines aim to help interventions in the city that move towards a sustainable urban regeneration model. These interventions should focus on the protection, conservation and improvement of the urban fabric by the innovative use of integrated approaches in sustainable urban policies (socio-economic and environmental perspectives) in vulnerable areas. The guide uses the SWOT (Strengths, Weaknesses, Opportunities and Threats) methodology by means of a detailed diagnosis of the area, followed by the CAME (Correct, Adapt, Maintain and Explore) methodology, to propose effective intervention strategies.
\end{abstract}

Keywords: urban regeneration, vulnerable areas, SWOT methodology, CAME methodology, urban policies.

\section{INTRODUCTION}

In recent decades, urban interventions have focussed on vulnerable areas [1]. Urban sustainability depends on a myriad of complex variables, where marginality and social exclusion are key factors to consider. Different studies show that residential and urban vulnerability are usually linked to the social vulnerability and the rehabilitation of vulnerable areas entails social inclusion [2]-[4].

In this context, national and local governments are implementing urban policies to promote the rehabilitation and regeneration of vulnerable urban areas [5]. The Regional Valencian Government (East Spain), through Law 5/2014, 25 July, Territorial Planning, Urban Planning and Landscape for the Valencian Community and Ammends Law 1/2019, 5 February (Ley 5/2014, de 25 de julio, de la Generalitat, de Ordenación del Territorio, Urbanismo y Paisaje, y las modificaciones de la Ley 1/2019, de 5 de Febrero, de la Comunitat Valenciana, LOTUP), promotes the prioritisation of urban interventions in vulnerable areas. This work presents a proposal to rehabilitate a previously defined vulnerable area in the city of Castellón. To do so, an in-depth analysis of the area was done to make a comprehensive diagnosis by considering different urban (U), building (B), socio-demographic (SD) and 
socio-economic (SE) categories. It acts as a starting point to recommend tailored measures of urban regeneration. In this work, the suggested measures will be presented and urban category measures will be explained in detail to illustrate the undertaken procedure.

\section{BACKGROUND}

The work conducted in this study is based on two previous studies. The first is the guide developed by the Regional Valencian Government, Directrices para el desarrollo de Estrategias de Regeneración Urbana para municipios de la Comunidad Valenciana (Guidelines to Develop Urban Regeneration Strategies in the Valencian Region, ERU) [6]. This guide aims to help local administrations and municipalities to set up a battery of strategies for urban regeneration in their local contexts. It presents a standardised methodology that results in the development of datasheets where some action lines are suggested, together with the economic estimation of interventions.

This methodology was basically adopted to undertake this work, but was completed using the information available in the second study. This is a complementary study that accompanies the recently developed Land-Use Plan, which defines vulnerable areas in the city of Castellón (northern Valencian Region). It delimits 17 vulnerable areas in the city to be prioritised when undertaking urban interventions. They are called Areas of Rehabilitation, Regeneration and Urban Renewal (ARRU) [7]. By way of example, we selected ARRU number 1 in the area named Castalia-La Guinea (Fig. 1).

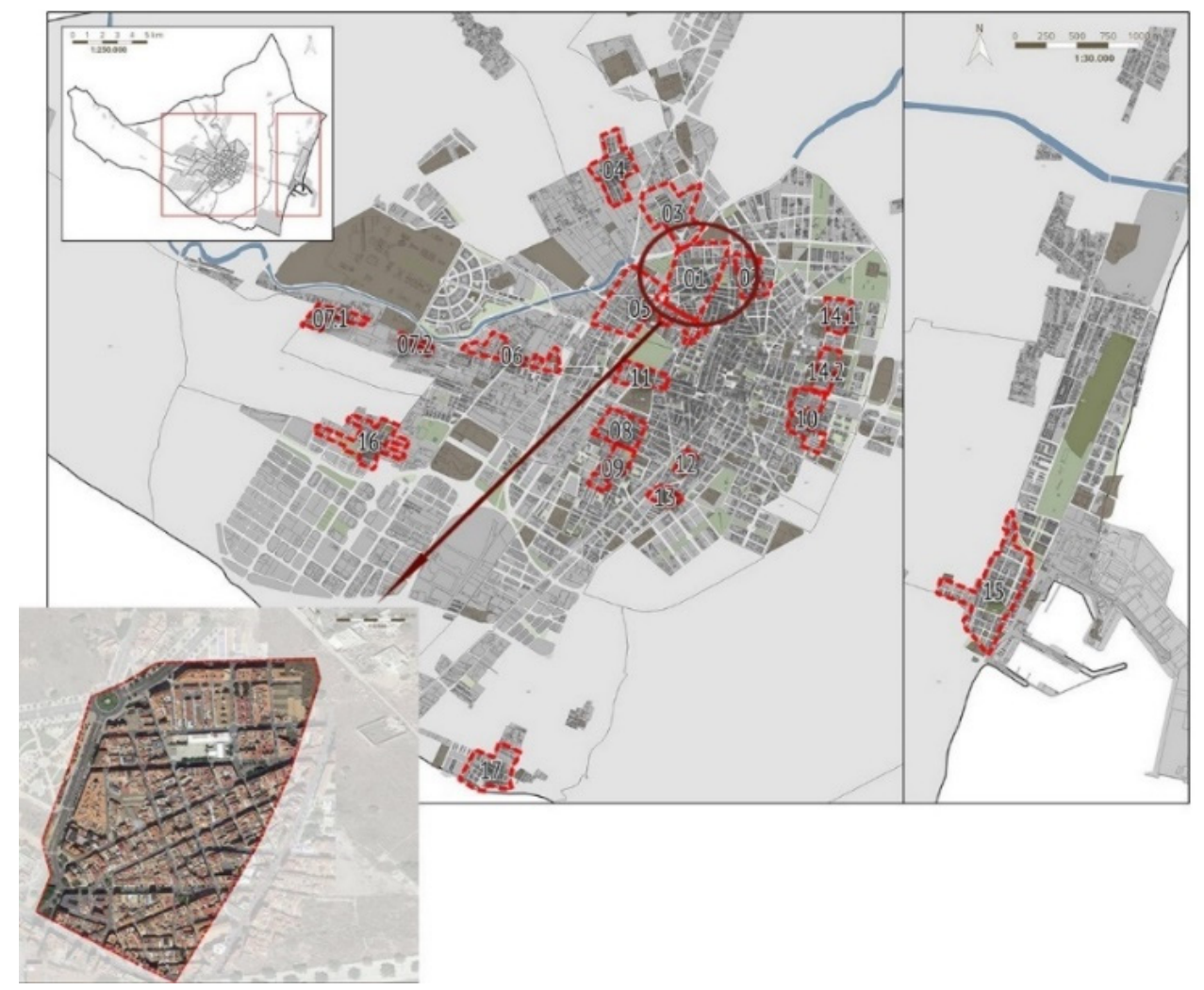

Figure 1: ARRU definition and location of ARRU01. 
This study implies added value for many reasons. On the one hand, it provides more accurate detailed information. While the ERU methodology is based on nine general indicators, the ARRU study draws up a list of 29 ad hoc indicators specifically adapted to the city of Castellón. The ARRU definition allowed a comprehensive view of the physical, technical, economic and social features of the urban areas in the city to be seen. On the other hand, data were adapted to a geographically delimited area by using a GIS tool. Moreover, it procures valuable information of participatory processes implemented in the study to obtain a social-oriented view, together with the technical perspective. This comprehensive information permits an accurate diagnosis that leads to the proposal of urban regeneration strategies that perfectly adapt to the specificities of the areas.

\section{METHODOLOGY}

Fig. 2 shows the basic four steps suggested by the ERU. The dark shaded cell of the diagram represents the introduction of the information collected from the ARRU study for the selected vulnerable area. Each stage is explained in the following subsections.

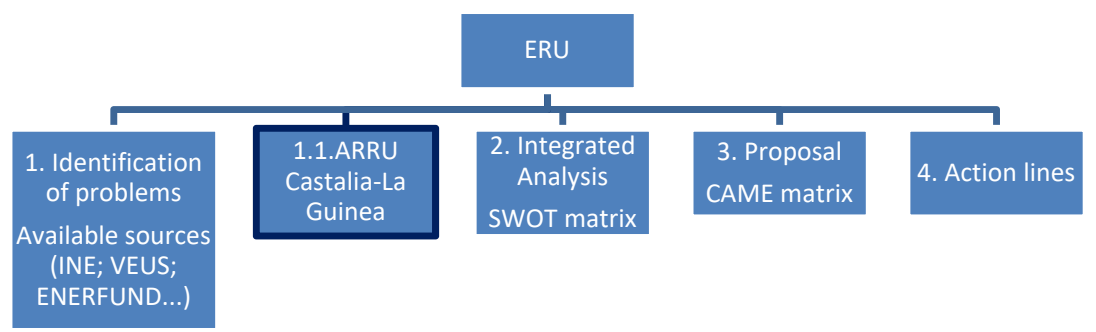

Figure 2: Methodology ERU + ARRU.

\subsection{Stage 1: Identification of problems}

The stage to identify problems is a determining phase for the result of renovation or reconstruction of urban spaces. It requires understanding not only the occupied urban area, but also the immediate surroundings and their area of influence. This stage aims to collect the first general data about the city, and more specifically about the selected urban area. It also aims to identify existent urban planning tools, other studies of the area, potential funds, etc. According to the methodology, participatory processes should also be included to gain a better picture of the social situation and to include the citizen view. This preliminary recognition allows the variables to be processed in the subsequent diagnostic status to be correctly identified. In this stage a draft list of potential interventions must be suggested.

\subsection{Stage 2: Integrated analysis}

The objective of this stage is to identify the needs and problems of the selected area, as well as its assets and potentials. They can be grouped by categories of analyses and can be presented by specifying strengths, weaknesses, opportunities and threats in a SWOT matrix. Strengths are those elements and characteristics of the urban system that provide strength and durability. Weaknesses are those elements and factors of the urban system that introduce 
fragility and unbalance into it or, in other words, the limitations that make the system vulnerable, unstable or unsustainable. Opportunities are external factors to the specific study field that enhance the system's strength and durability. They may also consider any future action that solidly contributes to the system. Threats are external factors to the specific study field that introduce fragility and unbalance into the system or any future action or factors of the system that, if not corrected, increase its fragility, or even cause it to collapse.

Various sources can be used. ERU suggests using the tool Viewer of Sensitive Urban Spaces of the Valencian Government VEUS [8]. This tool has been developed by the Valencian Cartographic Institute and the Valencian Government to be applied to municipalities in the Valencian Community. It permits vulnerable areas to be identified using a basic list of nine indicators, grouped into three categories, each with three indicators: $\mathrm{R}$ for residential category, formed by the indicators: R1 average built area/inhabitant; R2 cadastral value in $€ / \mathrm{m}^{2}$; R3 represents the percentage of dwellings that lack essential accessibility; E the socio-economic category formed by the indicators; E1 reflects the population with no level of studies; E2 represents the unemployment rate; E3 considers the poverty risk and social exclusion; D is the socio-demographic category, formed by three indicators measured as percentages that represent: D1, the vulnerable population; D2 vulnerable dwellings; D3, the immigrant population. They can all obtain a value 1, 2 or 3, meaning low, medium or high, according to their thresholds values, and can result in three types of vulnerability: Comprehensive vulnerability, Polyvulnerability and Residual Vulnerability.

Another source of information suggested by ERU is IEE-Cv [9]. It consists in a technical report about the technical aspects of the buildings regarding their energy performance, accessibility and conservation. It is compulsory for buildings over 50 years. They must be signed by professionals such as architects or technical architects, and must be registered in the Official Register of the Valencian Community.

The guide suggests using any other source of information that could add valuable data for research purposes.

\subsection{Stage 3: Proposal}

Based on the previous stages, the CAME matrix is built (Correct, Adapt, Maintain and Explore). This new matrix concludes in the strategies, needs or Challenges $\left(\mathrm{C}_{\mathrm{i}}\right)$ for category i, starting points to suggest and develop effective intervention strategies.

\subsection{Stage 4: Lines of Action}

In this stage, some Lines of Action ( $\left.\mathrm{LA}_{\mathrm{ij}}\right)$ are developed. being $j$ the number of LA to solve the $\mathrm{C} i$. Basic guidelines and operations are established to carry them out and the specific objectives that each of them pursues. Some summary sheets are built with the description and the estimated budget for each $\mathrm{LA}_{\mathrm{ij}}$.

\section{CASE STUDY: AREA CASTALIA-LA GUINEA, CASTELLÓN DE LA PLANA}

\subsection{Stage 1: Identifying problems}

Castellón de la Plana is a medium-sized Spanish coastal city with about 170,000 inhabitants, located in east Spain. All the areas identified in Castellón de la Plana in ARRU study present important vulnerability traits, although symptoms of vulnerability are not always manifested in all the categories evaluated. 
To carry out this study, ARRU Castalia-La Guinea has been selected because it is an area in which all categories of vulnerability converge, according to the simplified model developed by Ruá et al. [4].

The neighbourhood is located in the north-western part of the city, limited to the north by the Castalia Stadium and to the northeast by the old riverbed, which nowadays it is one of city's the main channels of communication. It is formed by part of census sections 08001 , 08002, 08003 and 08005. The main data are:

- Population: 6,214 inhabitants.

- Total area: 208,793.40 $\mathrm{m}^{2}$.

- Number of buildings: 725 units.

- Number of dwellings: 3,382 units.

- Total built area: $336,864 \mathrm{~m}^{2}$.

- Percentage of residential area over total: $77.64 \%$.

The area (Fig. 3) is characterised by high levels of immigration, and by old and lowquality buildings that lack appropriate accessibility conditions. The neighbourhood was planned from the late 19th century as part of the small extensions that projected in different parts of the city, but its development did not occur until the 1960s and 1970s as a result of the growth that the city underwent due mainly to immigration. The incorporation of green areas was not contemplated and the urban fabric of the neighbourhood is composed of narrow pavements. There are municipally owned social housing blocks and the building typologies include mainly buildings of four, five or six floors, predominantly without lifts. Together with the buildings for residential use, an industrial fabric is formed by small warehouses and old industrial buildings, some of which are unoccupied, and commercial premises are scarce.

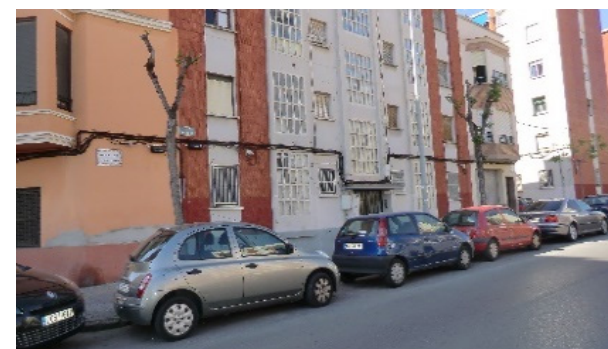

(a)

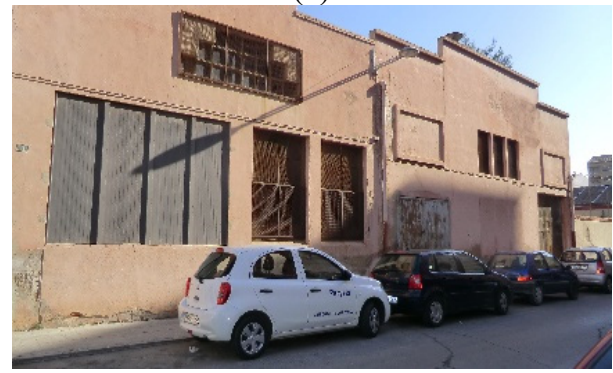

(c)

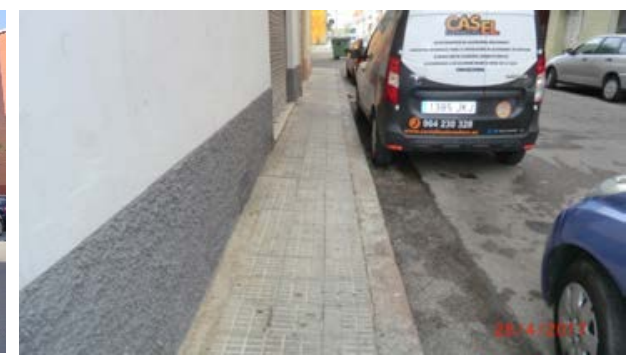

(b)

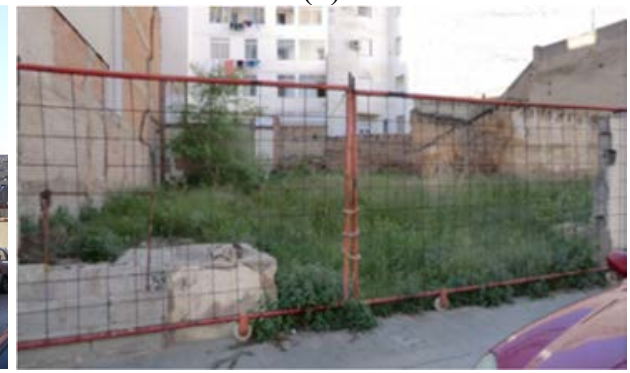

(d)

Figure 3: (a) Obsolete buildings; (b) Narrow pavements; (c) Abandoned warehouse; and (d) Vacancy lot. 
The main sources of information are as follows.

VEUS: The guide ERU suggests using the VEUS tool. Census sections 08002, 08003 and 08005 are polyvulnerable, but section 08001 presents residual vulnerability. As the selected area is not the sum of the evaluated census section, the methodology suggests calculating the weighted mean by considering the area of each census section included in the selected area. Therefore, the area is polyvulnerable.

IEE.CV: Another source recommended by ERU is IEE-Cv. However, only a very scarce representation of the buildings has actually been registered, so this source proves useless. So, this section has been completed with a detailed field work in the ARRU study.

Other sources: More macroinformation was obtained from the Atlas of Urban Vulnerability of the Spanish Ministry [10] and the National Statistics Office (INE). A previous study linked to the technical aspects of buildings, ENERFUND - Energy Retrofit Funding rating tool [11], developed by the Valencian Institute of Building (IVE), geolocates the Energy Certificates of more than 300,000 properties according to the Horizon 2020 programme of the European Commission. With this application, it is possible to obtain a representative number of the energy performance certificates presented in the area. According to this tool, 159 certificates are registered, most with low ratings: 53 corresponding to the letter $\mathrm{G}, 16$ to F, 72 to $\mathrm{E}$, and only three to letter $\mathrm{C}$ and two to $\mathrm{B}$, and no A qualification certificate is registered.

ARRU study: This study was performed using two scales: a previous macrodata collection and a second level with more accurate detailed information. In this first scale, data were obtained according to the census section, which constitutes an administrative border, but does not necessarily correspond to a specific urban area or neighbourhood. In the second scale, information was adapted to a geographically defined area, which presents homogeneous urban, technical, socio-economic features. To do so, a GIS tool was implemented. This very much improves the reliability of the results as the analysis is based on more accurate information. The study evaluated 29 indicators and presented vulnerability in 20 of them and non-vulnerability in the rest. Thus, the area was polyvulnerable on the whole. Table 1 summarises the main results obtained from the study.

Table 1: Indicators for ARRU1 (V: vulnerable; VN: no vulnerable).

\begin{tabular}{|c|c|c|c|c|c|}
\hline & Description & Vul. & & Description & Vul. \\
\hline \multirow{4}{*}{$\triangleright$} & Building Density & $\mathrm{V}$ & \multirow{12}{*}{ के } & Overcrowding & $\mathrm{NV}$ \\
\hline & Proximity to public transport & NV & & Population $\geq 65$ years & NV \\
\hline & Vacant lots & $\mathrm{V}$ & & Immigrants & $\mathrm{V}$ \\
\hline & Resident-commercial balance & $\mathrm{V}$ & & Population $<15$ years & $\mathrm{V}$ \\
\hline \multirow{4}{*}{$\oplus$} & Energy Efficiency & $\mathrm{V}$ & & Ageing 65/15 & NV \\
\hline & Renewable energy & V & & Municipal Social housing & $\mathrm{V}$ \\
\hline & Conservation ( $\%$ fair-bad) & NV & & EIGE's Social housing & NV \\
\hline & Constructive Quality ( $\% 6-9)$ & NV & & Children's vulnerability & $\mathrm{V}$ \\
\hline \multirow{6}{*}{ 桴 } & Social subsidies & $\mathrm{V}$ & & Social services assistance & $\mathrm{V}$ \\
\hline & Dependence subsidies & $\mathrm{V}$ & & Children's education & $\mathrm{V}$ \\
\hline & Absenteeism from school & V & & Noise complaints & $\mathrm{V}$ \\
\hline & Tax base & $\mathrm{V}$ & & Social mediation services & $\mathrm{V}$ \\
\hline & Cadastral value $\left(€ / \mathrm{m}^{2}\right)$ & NV & & & \\
\hline & Social subsidies & $\mathrm{V}$ & & & \\
\hline
\end{tabular}


The selection of the appropriate indicators was made by a panel of experts, assisted by information collected from citizens. Some meetings organised by the Municipality in distinct neighbourhoods gave the opportunity to collect citizens' requests and complaints about different issues linked to their city: urban complexity, public space, land occupation, infrastructures, buildings, dwellings, mobility, waste and social cohesion. Specific social techniques were followed to collect the views of three vulnerable groups, the elderly, women and children, and the expert opinions of Social Services technicians of the Municipality about social problems in vulnerable areas.

The results showed that, regarding technical aspects, buildings' energy performance or building density are important aspects to improve. When looking at social problems and dependence subsidies, a vulnerable situation appeared as regard social aspects.

\subsection{Stage 2. Integrated analysis: SWOT matrix}

All the previous information was inputted and arranged in a SWOT matrix, structured by four categories: U, B, SD and SE, following the same structure adopted in the ARRU study. The matrix is presented in Fig. 4.

\section{STRENGTHS \\ Good access to public transport (U) \\ Proximity to green areas (U) \\ Proximity to city centre $(\mathrm{U})$ \\ Proximity to public amenities (U)}

\begin{tabular}{|l} 
WEAKNESSES \\
High building density (U) \\
Lack of green areas (U) \\
Bad maintenance, lack of accessibility in public space (U) \\
High percentage of old low-quality buildings (B) \\
Obsolete buildings with no lift (B) \\
Buildings with very low energy performance (B) \\
Many abandoned lots and buildings (B) \\
High percentage of elderly people (SD) \\
High percentage of immigrants (SD) \\
High degree of subsidies dependence (SE) \\
High absenteeism from school (SE) \\
Low level of education (SE) \\
Many conflicts requiring police interventions (SE) \\
High unemployment rate (SE)
\end{tabular}

\section{OPPORTUNITIES}

Improve pedestrian mobility and sustainable mobility (bike lanes) (U)

Abandoned lots and buildings can be reused (B)

Rehabilitation of building stock to improve quality of life (B)

New jobs linked to neighbourhood regeneration (SE)

Increased real state value (SE)

Commercial premises activated (SE)

\section{THREATS}

Irreversible deterioration of housing stock (B)

Deterioration of public spaces (U)

Reduced appropriation of public spaces (U)

Gentrification (SE)

Low social cohesion (SD)

Ageing population (SD)

Social exclusion risk of vulnerable populations (SD)

Increase in insecurity linked to marginality (SD)

Vacancy of residential stock which leads to a reduction in premises, and the abandonment of public spaces $(\mathrm{U})$

Energy poverty situations (SE)

Figure 4: SWOT matrix of Castalia-La Guinea. 


\subsection{Stage 3. Proposal: CAME matrix}

From the SWOT matrix, the CAME matrix was developed. Both matrices can be developed by mixing the four considered categories (urban, building, socio-demographic and socio-economic) or considering each category. The Challenges inferred for category are:

- Urban: $\mathrm{C}_{1}$. Reverse the process of urban deterioration, improve the environment, conditioning green spaces, and propose leisure activities for children, young people and elderly.

- Socio-demographic: $\mathrm{C}_{2}$. Reduce the risk of social exclusion and offer better living conditions to vulnerable groups of population.

- Socio-economic: $\mathrm{C}_{3}$. Offer new opportunities for inhabitants of the neighbourhoods. Promotion of identity.

- Building: $\mathrm{C}_{4}$. Energy performance and accessibility improvement in buildings.

For example, for the urban category, Fig. 5 shows the CAME matrix.

\begin{tabular}{|c|c|c|}
\hline $\begin{array}{c}\text { MANTAIN } \\
\text { Good access to public transport } \\
\text { Proximity to green areas } \\
\begin{array}{c}\text { Proximity to city center } \\
\text { Proximity to public amenities }\end{array}\end{array}$ & $\begin{array}{c}\text { EXPLORE } \\
\text { Improved pedestrian mobility and } \\
\text { sustainable mobility (bike lanes) } \\
\text { Vacancy of residential stock, which } \\
\text { leads to a reduction in premises and the } \\
\text { abandonment of public spaces }\end{array}$ \\
\hline CORRECT & CAME & ADAPT \\
\hline $\begin{array}{c}\text { High building density } \\
\text { Lack of green areas }\end{array}$ & Rederioration of public spaces \\
\hline $\begin{array}{c}\text { Bad maintenance, lack of accessibility in } \\
\text { public spaces }\end{array}$ & \\
\hline
\end{tabular}

Figure 5: CAME and the inferred Challenge for the urban category $\left(\mathrm{C}_{1}\right)$.

\subsection{Stage 4: Lines of Action}

The last step of the methodology was to propose LA. They aim to materialise interventions to solve the $C_{i}$ deduced from the previous stage. The $L_{i j}$ suggested for $C_{i}$ category are graphically presented in Fig. 6, and they are:

For category $\mathrm{C}_{1}(\mathrm{U})$ :

- $\mathrm{LA}_{11}$ Promote the recovery of the urban fabric and improve the connectivity of public spaces.

- $\mathrm{LA}_{12}$ Reorder, recover and condition public spaces and existing green areas. Encourage urban appropriation: provide favourable conditions for the use of public spaces.

- $\quad \mathrm{LA}_{13}$ Sustainable mobility: improve cyclist network and pedestrian accessibility. 
For category $\mathrm{C}_{2}(\mathrm{SD})$ :

- $\mathrm{LA}_{21}$ Improvement of infrastructures equipment and public spaces to promote social relations and social inclusion.

- $\mathrm{LA}_{22}$ Consider gender mainstreaming in the design of urban interventions.

For category $\mathrm{C}_{3}(\mathrm{SE})$ :

- $\mathrm{LA}_{31}$ Foment local commercial activity.

- $\mathrm{LA}_{32}$ Improve skills for unemployed.

For category $\mathrm{C}_{4}(\mathrm{~B})$ :

- $\mathrm{LA}_{41}$ Promote rehabilitation, renovation and access to decent housing.

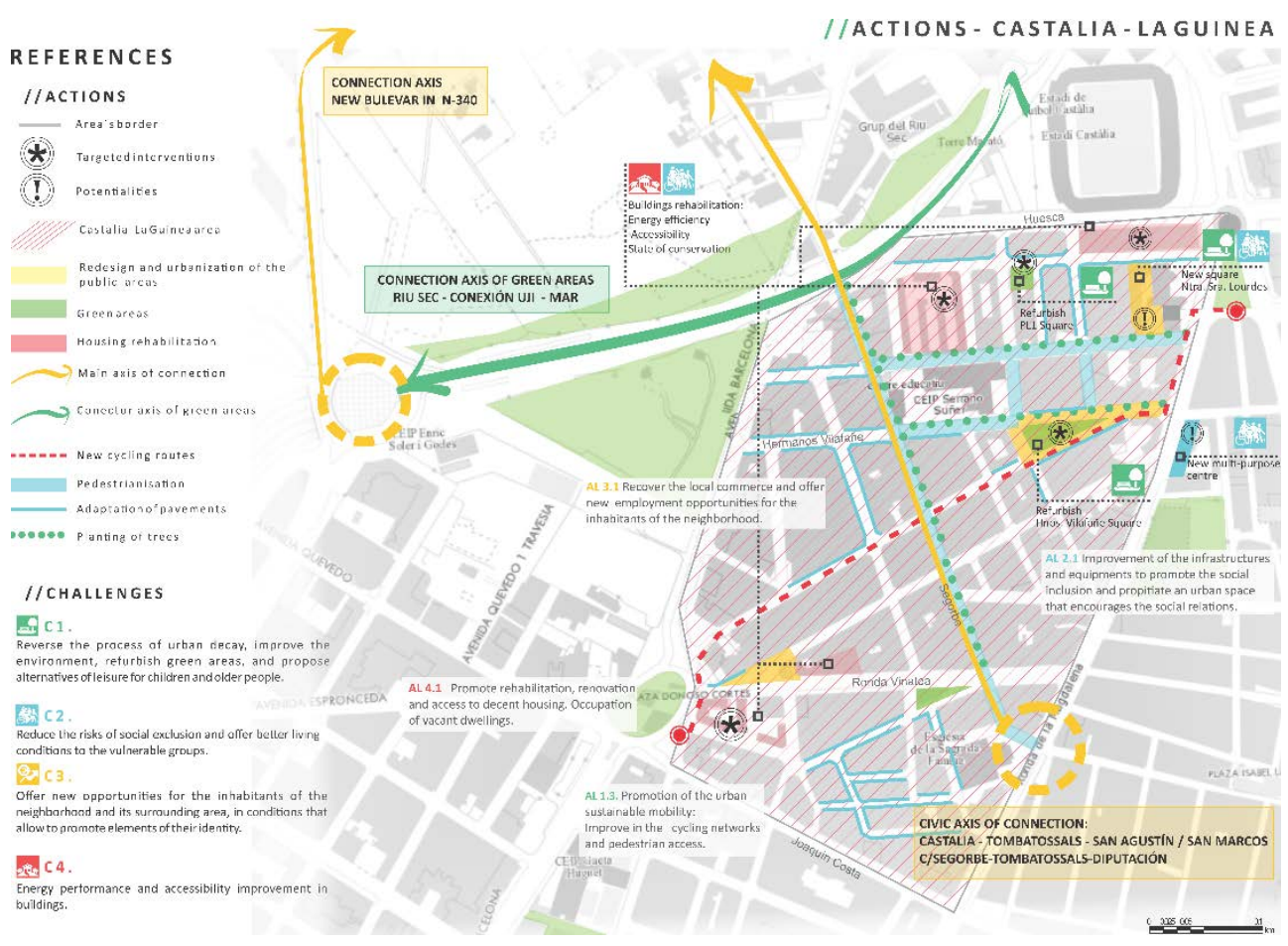

Figure 6: Plan representing Challenges and Lines of Action.

In this work the $\mathrm{LA}$ for $\mathrm{C}_{1}$ and $\mathrm{C}_{4}$, Urban and Building categories, were developed. Each LA is presented via a datasheet with the following information:

- Brief description and main objectives.

- Complexity level: low, medium, high.

- Priority level: low, medium, high.

- Interventions with detail.

- Economic estimation in euros.

- Recommended indicators for monitoring the fulfilment of the objectives.

Fig. 7 presents the detail of the datasheet $\mathrm{LA}_{11}$ Promote the recovery of the urban fabric and improve the connectivity of public spaces, as a way of example. 


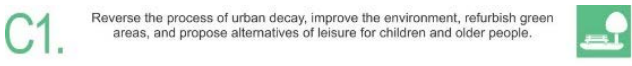

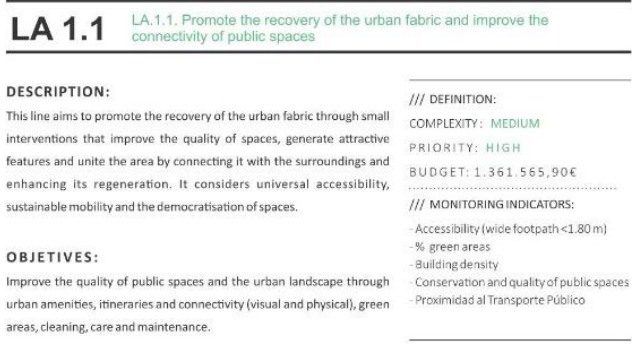

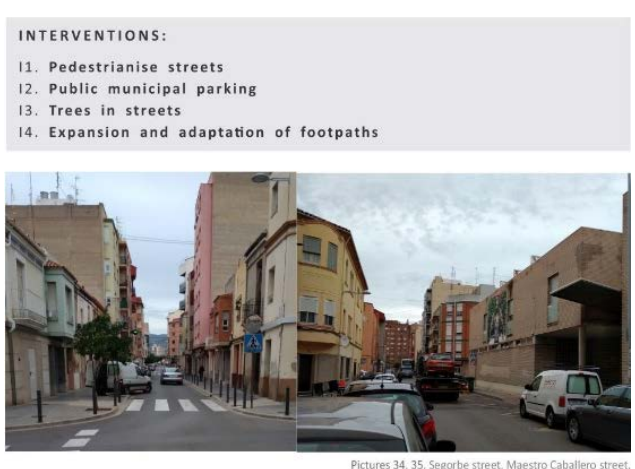

Pictures 34,35 . Segorbe street, Maestro Caballiter street,

\section{Streets to be pedestrianised:}

Segorbe Street: From north to south. It will cross the neighbourhood diagonally from Ronda Magdalena to Riu Sec Avenue. It will connect the Castalia stadium Avenue, ARRU Tombatossals through Tombatossals gustín and San also connect with the ARRU San Avenue.

- The perimeter streets to the Castalia Public School: Segorbe street, Maestro Caballero street, Hemanos illafana street and Penyagolosa street. Toimprove the school.

-Work on the lower section of Nules Street to connect the street Caballero Maestro to the triangular square among the streets of Vilafaña, Vinaroz and Teniente

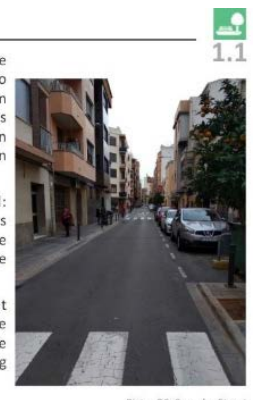

12.Public municipal parking:

The pedestrianisation of streets and the provision of bicycle lanes will reduce the number of parking space on the surface, so this solution aimstoreserve an are for municipal public parking with about 300 spaces. Some of unbuiltplotscould be adapted.

\section{Trees in streets:}

Plant trees in tree pits along pedestrianised streets, according to the layout set out in the graphic documentation. They should allow sunlight to pass in winter and provide shade in summer to thermally egulate the urban space. Theycould al socool adjacen façadesasa passiveenergyefficiencymeasure.

14. Expansion and adaptation of footpaths:

Expand footpaths currently less than $1.8 \mathrm{~m}$ wide. Maintenance works wherever needed. Ad accessibilityramps whereverneeded.

Figure 7: Datasheet for LA.1.1. 


\section{CONCLUSIONS}

In this work, the proposal of strategies of urban regeneration is presented using a case study of a vulnerable area in Castellón. The existing methodology proposed by the Regional Valencian Government help to standardise the process is a valuable tool to gain a general idea of the basic strategies of urban regeneration. However, profound knowledge of the local context is necessary to draw up tailored strategies.

In this work, guide ERU, developed by the Regional Valencian Government, was applied due to its practical and easy use. It is formed by some stages that provide a comprehensive view of the analysed urban area. The guide recommends some useful tools that have been used in this study and also recommends using another sources whenever they are available.

In this case, we implemented the data of the ARRU study, which specifically aimed to identify vulnerable areas in cities. This study presents an accurate comprehensive analysis that completes previous analyses by adding ad hoc indicators, which were developed according to the city's specificities. Besides, calculations were made to adapt data to the actual geographical area by a GIS tool. It also citizens' views, obtained from participatory processes and vulnerable population groups. This enabled the quality of the results to improve, and provided an exact diagnosis with which to propose the appropriate strategies of urban regeneration. They were materialised through some practical datasheets that are a valuable tool to present and summarise main interventions.

\section{ACKNOWLEDGEMENTS}

We thank the INPRU-CS company and the Municipality of Castellón de la Plana for providing the data for research purposes. This research was supported by the Valencian Regional Government (Conselleria d'Educació, Investigació, Cultura i Esport de la Generalitat Valenciana) through Project [GV/2017/110].

\section{REFERENCES}

[1] Conway, M. \& Konvitz, J., Meeting the challenge of distressed urban areas. Urban Studies, 37(4), pp. 749-774, 2000.

[2] Alguacil, J., Instrumentos para el análisis y políticas para la acción. Presented at Foro de Debates: Ciudad y Territorio. Jornada La vulnerabilidad urbana en España, Madrid, Spain, 2011.

[3] Hernández-Aja, A. \& Rodríguez-Suárez, I., De la rehabilitación a la regeneración urbana integrada. Ciudades, 20, pp. 1-20, 2017.

[4] Ruá, M.J., Huedo, P., Civera, V. \& Agost-Felip, R., A simplified model to assess vulnerable area for urban regeneration. Sustainable Cities and Society, 46(101440), 2019.

[5] Schreiber, F. \& Carius, A., Ciudades inclusivas: planeamiento urbano para la diversidad y la cohesión social. La situación del mundo: informe anual del Worldwatch Institute sobre progreso hacia una sociedad sostenible, pp. 293-314, 2016.

[6] Directrices para el desarrollo de Estrategias de Regeneración Urbana para municipios de la Comunitat Valenciana, Versión V.2, Julio 2018. www.habitatge.gva.es/ documents/20558636/166160274/DIRECTRICES_ERU_V2_Julio_2018.pdf/72ef21 b7-702e-4151-99a8-f6e3c0b182a8. Accessed on: 29 Apr. 2019.

[7] García-Bernal, D., Huedo, P., Babiloni, S., Braulio, M., Carrascosa, C. \& Civera, V., Estudio y Propuesta de Áreas de Rehabilitación, Regeneración y Renovación Urbana, con Motivo de la Tramitación del Plan General Estructural de Castellón de la Plana, 2017. 
[8] Generalitat Valenciana. VEUS Tool. https://visor.gva.es/visor/index.html?, idioma $=$ es\&capasids=VEUS;4,3,2,1,0,. Accessed on: 30 May 2019.

[9] Generalitat Valenciana, IEE-Cv Tool. www.habitatge.gva.es/es/web/vivienda-ycalidad-en-la-edificacion/visor-cartografic-ieev.cv. Accessed on: 12 Mar. 2019.

[10] Ministerio de Fomento de España, Atlas de Vulnerabilidad Urbana. http://atlasvulnerabilidadurbana.fomento.es/. Accessed on: 15 Feb. 2018.

[11] ENERFUND Tool, http://enerfund.eu/. Accessed on: 6 Mar. 2019. 